\title{
Literatura ad usum delphini: José de Viera y Clavijo y su traducción de los cuentos para niños de Arnaud Berquin
}

\author{
Patricia MAUCLAIR \\ Université de Tours \\ mauclair.poncelin@univ-tours.fr
}

\author{
Jesús DÍAZ ARMAS \\ Universidad de La Laguna \\ jsdiaz@ull.edu.es
}

\section{Resumen}

José de Viera y Clavijo (Los Realejos, Tenerife, 1731-Las Palmas de Gran Canaria, 1813) es el autor de la primera traducción española, realizada en 1784, de una selección de los cuentos y las obras de teatro para niños reunidos por Arnaud Berquin (Burdeos, 1747París, 1791) en L'ami des enfants, publicación mensual que alcanzó veinticuatro entregas entre 1782 y 1783 y que también, en su mayor parte, eran traducciones de textos de autores alemanes, holandeses e ingleses, extraídos de publicaciones como Kleine Kinderbibliothek (17791784), de Campe o Der Kinderfreund (1776-1782), de Christian Felix Weisse, entre otras. Las traducciones/adaptaciones realizadas por Arnaud Berquin son muy libres y muestran una acomodación a la cultura francesa y a la filosofía ilustrada de este autor. De la misma manera, el ilustrado Viera y Clavijo, un avanzado escritor y un consumado y prolífico traductor, también se permitió muchas libertades a la hora de traducir los cuentos de Berquin. En este trabajo se señalan algunos de los importantes cambios que el traductor espańol introduce en sus versiones y se explican en las coordenadas culturales e ideológicas de la Espańa del siglo XVIII.

Palabras clave: Literatura del siglo XVIII. Literatura infantil. Traducción literaria. Ami des enfants (1782-1783). Cuentos de niños que instruyen divirtiendo (1784).

\section{Abstract}

José de Viera y Clavijo (Los Realejos, Tenerife, 1731-Las Palmas de Gran Canaria, 1813 ) is the author of the first translation into Spanish, made in 1784, of a selection of the tales and dramas written for children published by Arnaud Berquin (Bordeaux, 1747-París, 1791) in L'ami des enfants, a mensile publication that has got twelfe numbers between 1782 and 1783, and that were, almost the whole collection, translations of German, Dutch and English authors, extracted from publications as Kleine Kinderbibliothek (1779-1784), by Campe, or Der Kinderfreund (1776-1782), by Christian Felix Weisse, betwenn others. The thanslations/adaptationes made by Arnaud Berquin were very free, and they show an evident accomodation to the french culture and to the enlightenment philosophy of this author. No-

* Artículo recibido el 7/01/2019, aceptado el 7/10/2019. 
wadays, the enligtenment age author Viera y Clavijo, an advanted author and a expert and prolific translator, took many liberties in translating the Berquin's Tales. In this article, are shown some of the important changes introduced by the the spanish translator in his versions and they are explained in the cultural and ideological context of the Spain in the 18th century.

Key Words: Eighteenth Century Literature. Children's literature. Literary Translation. Ami des enfants (1782-1783). Cuentos de niños que instruyen divirtiendo (1784).

\section{Résumé}

José de Viera y Clavijo (Los Realejos, Ténérife, 1731-Las Palmas de Gran Canaria, 1813) est l'auteur de la première traduction espagnole, réalisée en 1784, d'une sélection de contes et de pièces de théâtre pour enfants réunis par Arnaud Berquin (Bordeaux, 1747-Paris, 1791) dans L'ami des enfants. Entre 1782 et 1783, cette publication mensuelle fit paraître 24 numéros qui, pour la plupart, étaient déjà des traductions de textes d'auteurs allemands, hollandais et anglais, extraits de publications telles que Kleine Kinderbibliothek (1779-1784), de Campe o Der Kinderfreund (1776-1782), de Christian Felix Weisse, notamment. Les traductions/adaptations réalisées par Arnaud Berquin sont très libres et montrent un accomodement à la culture française et à la philosophie éclairée de cet auteur. De même, Viera y Clavijo, esprit éclairé, écrivain audacieux, traducteur exigeant et prolifique, s'est accordé de nombreuses libertés au moment de traduire les contes de Berquin. Ce travail met en exergue les changements importants que le traducteur espagnol a introduits dans ses traductions qu'expliquent les références culturelles et idéologiques de l'Espagne du XVIII ${ }^{e}$ siècle.

Mots clé: Littérature du XVIII ${ }^{e}$ siècle. Littérature de jeunesse. Traduction littéraire. Ami des enfants (1782-1783). Cuentos de niños que instruyen divirtiendo (1784).

\section{Introducción}

La figura del escritor ilustrado José de Viera y Clavijo se ha puesto en relación recientemente (Díaz Armas y Mauclair, 2018) con los orígenes de la literatura infantil en lengua española por ser el autor, hacia 1767 , de la primera pieza dramática escrita para niños (la Loa de Adoración de Reyes) y de la primera traducción, terminada en 1784, de una selección de los textos incluidos en la publicación de Arnaud Berquin L'Ami des enfants, que vio la luz en París, en forma de entregas mensuales, entre enero de 1782 y diciembre de 1783. Hasta ese momento, la historiografía había venido considerando, como primera obra teatral española para niños, El niño desobediente, escrita en 1837 por Juan Eugenio Hartzenbuch para la reina Isabel II, que tenía entonces 7 años (Bravo-Villasante, 1983) y, como primera traducción al español de los textos de Berquin, la Biblioteca de buena educación o El amante de la ninez y de la juventud, de Julián de Velasco, publicada en Barcelona en 1792 (Ruiz de la Peña, 2003; 493; Bravo Villasante, 1983) ${ }^{1}$.

\footnotetext{
${ }^{1}$ Mientras que esta traducción de Viera no había recibido ninguna atención editorial hasta su reciente
} 
Los textos traducidos por Viera formaron parte de un manuscrito autógrafo titulado El amigo de los niños, entregado como regalo de despedida para sus pupilos, los hijos del marqués de Santa Cruz, en el que se incluían cuentos, poemas y obras de teatro extraídos de la mencionada colección de Arnaud Berquin, así como del Teatro de la Educación de Madame de Genlis y de los Idilios de Salomon Gessner. Tan solo se conserva una parte de estos textos en los dos testimonios existentes: el autógrafo recientemente hallado y publicado por Acosta Tejera y Aguiar Bobet (Viera, 2013) y que apenas difiere del segundo testimonio, la versión dada a la imprenta en Las Palmas de Gran Canaria a partir de 1803, también en forma de publicación periódica y sin intervención editorial del autor, con el probable título Cuentos de niños que instruyen divirtiendo: obra extractada de buenos autores, principalmente de la que con el titulo del Amigo de los niños publicó en París Mr. Berquin, y fue premiada por la Academia francesa como una de las más útiles para la educación.

Estos datos, que pueden establecerse con certeza gracias a los testimonios y a los documentos encontrados (Díaz Armas y Mauclair, 2018), y que adelantan las fechas indicadas hasta ahora (Bravo-Villasante-1983; Ruiz de la Peña, 2003), ponen a España en relación con el surgimiento, en torno al último tercio del siglo XVIII, de un tipo de literatura dirigida a niños y jóvenes que responde a unos nuevos planteamientos educativos y viene a producirse contemporáneamente en países como Alemania, Inglaterra y Francia (Soriano, 1999; Klingberg, 1983; Havelange y NièresChevrel, 2014): nuevas robinsonadas como Robinson der Jüngere, también de Campe (1779) y colecciones de cuentos y obras de teatro surgidas en publicaciones periódicas como Der Kinderfreund, de Christian Felix Weiße (1775 a 1782), Der Kinderfreund, del pedagogo Eberhard von Rochow (1776), Lessons for Children o Hymns in Prose for Children, de Anna Laetitia Baurbauld (1778-1779), Kleine Kinderbibliothek, de Joachim Heinrich Campe (1779-1784), Théâtre à l'usage des jeunes personnes, de Stéphanie Félicité du Crest, más conocida en la época como Mme de Genlis (17791780) o L'Ami des enfants, de Arnaud Berquin (1782-1783).

Muchas de estas obras se traducen casi inmediatamente y se publican en recopilaciones en las que no suele indicarse qué textos son traducidos y cuáles son originales. Por esta razón, es prácticamente imposible disociar las prácticas de la escritura y la traducción y, por ello, es la historiografía de la traducción la que ha señalado, para Francia, el período 1770-1789 como el del verdadero nacimiento de la literatura para niños y jóvenes, y precisamente de la mano de obras que son, en realidad, traducciones desde otras lenguas (inglés, alemán, holandés), como, entre otras muchas, la obra

publicación en el tomo 23 de las Obras completas de Viera y Clavijo -el dedicado a la Obra didáctica (Viera, 2013)-, la obra La espada, traducción de la pieza teatral L'épée, de Arnaud Berquin, ya había sido editada por Rafael Fernández (1991), aunque atribuyéndosela al propio Viera. Por último, la Loa de Adoración de Reyes, obra original de Viera y Clavijo, fue publicada también por Rafael Fernández en el volumen indicado en esta nota. 
de Marie-Élisabeth Boué (o Marie-Élisabeth de La Fite), autora de unos Entretiens, drames et contes moraux, à l'usage des enfants publicados en 1778 y 1783 (Havelange y Nières-Chevrel, 2014: 1232).

Efectivamente, los textos reunidos por Arnaud Berquin en L'Ami des enfants, como demuestran diferentes trabajos de los que un último estado de la cuestión puede verse en los de Nières-Chevrel (2014) y Havelange y Nières-Chevrel (2014), son también, en su mayor parte, traducciones/adaptaciones de las ya citadas colecciones de Rochow y Weisse, y muy pocas de las 124 obras publicadas en L'Ami des enfants - unas treinta- podrían ser obras de su autoría, y eso mientras no se encuentren nuevas fuentes para este pequeño número de piezas, de difícil localización a causa de la falta de correspondencia o incluso la ausencia de títulos en las publicaciones originales (Nières-Chevrel, 2014: 819). Así, 19 de las 21 piezas teatrales son traducciones libérrimas de Weisse, Engel, Campe, Stèphanie y Salzmann mientras que casi todos los cuentos y dialoguillos son versiones de textos de estos mismos autores o bien de Schummel, Gemmingen-Horberg o incluso de las Lessons for Children de Anna Laetitia Barbauld (Nières-Chevrel, 2014: 810; Havelange y Nières-Chevrel, 2014: 1232).

Berquin no solo tomó el nombre y los propios textos de las colecciones de Rochow o Weisse, sino también el planteamiento editorial (publicación periódica) y educativo: la educación moral a través de cuentos y pequeñas obras de teatro (una en cada entrega) destinadas a la representación, en el espacio doméstico, por padres e hijos (Soriano, 1999: 92).

En ese contexto se insertan los Cuentos de niños de Viera y Clavijo: el ilustrado canario adapta a la lengua española cuentos y obras de teatro para niños (y las ideas que los habían producido) que Berquin estaba, asimismo, traduciendo del inglés, el alemán o el holandés. Y al traducir a Berquin, a Mme de Genlis y a Gessner, el ilustrado canario se inscribe en esta misma línea que marca el surgimiento de la literatura infantil y en el que hemos de encuadrar también a los españoles Tomás de Iriarte, por su traducción -desde el francés- del Nuevo Robinson de Campe (Soubeyroux, 2011), y a Nicasio Gallego, Julián de Velasco o los editores asturianos de la publicación periódica de 1798 la Gaceta de los Niños, que recogen textos de o sobre Campe, Schummel, Weisse y Berquin (Ruiz de la Peña, 2003, pp. 496-498).

Viera y Clavijo, tan familiarizado - como todos los ilustrados de su entorno de Canarias o en Madrid, donde se encontraba en la época en la que terminaba su traducción- con las novedades editoriales francesas, debió de hacerse traer la publicación de Arnaud Berquin casi desde el momento de su aparición, aspecto que parece confirmar la correspondencia de los títulos con los de la publicación periódica, modificados en posteriores ediciones de los cuentos del francés (por ejemplo, "El desayuno", "Le déjeuner» en la edición periódica pero singularizado en ediciones posteriores como "Le déjeuner et les trois gâteaux » o como "Les trois gâteaux »). Por otro lado, 
la traducción de Viera sigue el orden en que los textos fueron publicándose en L'Ami des enfants, desde su primera entrega en enero de 1782, de la que elige el primero de los cuentos, "Le petit frère » ("El hermanito"), hasta la penúltima, de noviembre de 1783, de la que recoge «La perruque, le gigot, les lanternes, le sac d'avoine et les échasses", traducido como "La peluca y los zancos", añadiendo a continuación la obra de teatro "L'épée ", publicada en la tercera entrega parisina, de marzo de 1782, y un texto que no parece ser traducción de la obra de Berquin y titulado "Él es una alhaja”.

Viera y Clavijo formó parte, así pues, de un grupo de pensadores, escritores, divulgadores científicos, preceptores y traductores europeos (el ilustrado canario fue todas estas cosas) convencidos de que un instrumento decisivo para la difusión de las ideas ilustradas era disponer de textos informativos y literarios para niños que los instruyeran en los principios de la razón y los rudimentos de la ciencia y que, alejándose del mundo supersticioso y mágico del cuento popular, propusieran una nueva concepción de la educación de la ciudadanía en consonancia con las ideas de la Ilustración. Surge, así, un nuevo tipo de literatura, de carácter urbano y realista, que tiene como protagonistas a niños de la burguesía y que plantea dilemas de carácter moral a sus lectores infantiles, siendo los propios niños los que tienen que encontrar soluciones por sí mismos y limitándose el papel de los actantes adultos (padres y preceptores como personajes secundarios) a facilitar la reflexión del niño a través del diálogo y la perspectiva mayéutica.

Un análisis comparativo entre los cuentos de Berquin y las versiones del ilustrado canario pueden proporcionarnos interesantes datos acerca de las similitudes y diferencias apreciables entre ambos proyectos literarios y didácticos y acerca de qué es lo que ambos autores pensaban sobre el tipo de literatura que debía destinarse a la infancia. Desgraciadamente, la pérdida de la primera y más completa obra de Viera y Clavijo, el manuscrito entregado a los hijos del marqués de Santa Cruz en 1784, solo puede darnos una aproximación a estos interrogantes, pues en la única obra conservada, la publicación periódica iniciada en 1803 , no sabemos si hubo participación del autor -su nombre, al parecer, no aparecía al frente de la edición- y se trataba de una impresión por entregas y para un número muy escaso de suscriptores, por lo que quizá estuviera limitada en el espacio del número de pliegos y páginas de cada número, lo cual podría explicar, hipotéticamente, la sistemática estrategia reductora del traductor canario.

\section{El proyecto educativo de Arnaud Berquin: L'Ami des enfants}

Entre las ideas defendidas por Berquin en su obra se reconocen algunas características importantes que hay que tener en cuenta al valorar sus obras para niños y que parten de las ideas educativas de Rousseau o Locke: la educación religiosa, facilitada a través de la contemplación de la Naturaleza, es responsabilidad de los padres; la 
educación se realiza en la esfera privada, mientras que la instrucción debe ser responsabilidad de los poderes públicos; además, hay que hacer desaparecer los prejuicios en favor de la razón y tomar la amistad como la base de la relación entre el niño y el educador (Lhérété, 1985). Dios se revela en su creación, así que el descubrimiento del Creador se hace partiendo de sensaciones y emociones positivas, borrándose toda idea espantosa de la Deidad, ya que el niño es naturalmente bueno. En cuanto al discurso moral, Berquin alaba la moderación, critica la pasión del lujo y el juego, está a favor de una moral laica y piensa que hay que fundar el interés particular en el interés general (Baudron, 2009, 43-45).

La innovación que supuso la obra de Berquin y las de sus fuentes debe ser analizada en el contexto de la ilustración: aun dirigidos a los hijos de los burgueses, en sus cuentos hay una concepción novedosa de la nueva moral que se propone en el nuevo estado de cosas de la Revolución francesa: la moral, la virtud, es un ideal universal al que deben aspirar todas las clases sociales. Como ha dejado dicho Marc Soriano (1999: 92):

La virtud en todas sus formas, como en Montesquieu, es la nueva regla de vida, por oposición al honor aristocrático, desvalorizado y anacrónico. La moral, rehabilitada, se convierte en la consigna de un nuevo reacomodamiento, que une al campesino con el hijo del notario y -ipor que no?- con el hijo del noble de provincias. Berquin ha frecuentado a los girondinos y su obra revela su proyecto de sociedad, la igualdad y la felicidad alcanzadas a través de la virtud: "no puedo dejar de reconocer que ese pequeño campesino lleva grabada en su alma la auténtica nobleza”.

En cuanto a las traducciones de Berquin, sus versiones de los cuentos de Campe y Weisse (entre otros) son muy libres y afectan a la lengua que hablan los personajes, mucho más expresiva y ágil, así como al estilo del narrador, más conciso y elíptico que el de sus modelos alemanes, pero también a las concepciones religiosas (la religiosidad de signo protestante, más que desaparecer en aras de una adaptación al catolicismo, se diluye en el deísmo profesado por el autor) e incluso, y esto es especialmente importante, a la representabilidad de estas piezas, que están pensadas para que los niños las pongan en escena ante la familia: en la advertencia a su publicación de enero de 1782, Berquin explicaba por qué era necesaria esa representación: «leur faire acquérir de bonne heure une contenance assurée, des grâces dans leurs gestes et dans leur maintien, et une manière aisée de s'énoncer en public " (Berquin, 1782: I, IX).

\section{Viera y Clavijo y su labor pedagógica}

Por su parte, José de Viera y Clavijo fue un prolífico escritor y divulgador científico en consonancia con su tiempo, como muchas de sus actividades demues- 
tran: escribió un importante Diccionario de Historia Natural de las Islas Canarias; una monumental y celebrada Historia de las Islas Canarias; organizó un gabinete para comunicar, en Madrid y luego en Gran Canaria, los avances científicos aprendidos en París en las clases de matemáticas, física, química o ciencias naturales de Sigaud de Lafond, de Sage y de Bomare; escribió ese tipo de poesía didáctica tan común en la época para dar cuenta de los avances del progreso (Los aires fixos, Las bodas de las plantas, Los jardines o el arte de hermosear paisajes, Al recibimiento hecho en Santa Cruz a la expedición de la vacuna, Al globo aerostático que de orden del Rey hizo elevar en Aranjuez don Pedro Gutiérrez Bueno ${ }^{2}$ ) y dedicó gran parte de su tiempo y sus esfuerzos a la traducción, que entendía como un servicio realizado en favor de la circulación de las ideas ilustradas.

Viera había viajado por Europa y disfrutado de duraderas estancias en Francia, donde había entrado en contacto, a través de su amigo La Blancherie, con el mundo literario parisino, frecuentando tertulias literarias, La Comedie Française, la Academia Francesa. Se carteó e intercambió información sobre observaciones geográficas y botánicas con científicos y divulgadores del pensamiento científico como Cavanilles, La Lande, el abate de l'Épée, Condorcet. La nutrida lista de obras y autores franceses que tradujo muestran su modernidad, su afrancesamiento y en ocasiones su osadía (teniendo licencia papal para leer libros prohibidos, también los hizo llegar a sus contemporáneos en versiones manuscritas o impresas de autores como Voltaire), y los dos polos de sus intereses (los literarios y los científicos): Delille, Boileau, Perrault, La Harpe, Chamfort, Racine, La Serre, Roucher, Mme Deshoulières, Carlos Morel de Vindé (Cioranescu, 1954; Padrón, 2019).

Por todas estas realizaciones, y no solo por tratarse de un autor inmerso en la ideología ilustrada de su época, tan dada a la poesía didáctica y el teatro con función educativa, probablemente la dimensión fundamental en la obra de Viera y Clavijo es la pedagógica, aunque también cultivó otras muchas facetas dentro de lo literario: aunque mal conocida e injustamente minusvalorada, la poesía de Viera y Clavijo no es una de las que sale peor parada en una valoración ecuánime y puesta en el contexto de lo que pudo ofrecer la poesía del siglo XVIII; por otro lado, su prosa, ya celebrada por Alejandro Cioranescu, entre otros muchos (Cioranescu, 1954), ha dado algunas de las mejores páginas de la literatura del XVIII español, especialmente la de sus diarios de viaje y su copiosísima correspondencia.

En Viera y Clavijo, efectivamente, la didáctica es una de sus dimensiones fundamentales, si no la primera. Al menos, la que produjo el mayor número de páginas, pues en ella pueden encuadrarse, de alguna forma, no solo los poemas didácticos o las obras escritas para niños, sino también otros frutos de su esfuerzo, ya que la propia

\footnotetext{
${ }^{2}$ Algunas de las traduciones del propio Viera son, precisamente, de poemas didácticos como La Elocuencia, de De La Serre (Las Palmas de Gran Canaria, 1787).
} 
actividad de la traducción o de la difusión científica fueron concebidas por Viera y Clavijo como un servicio realizado para el progreso de su sociedad, su patria y su lengua y, por tanto, como una de las exigencias éticas conducentes a la educación de la nueva sociedad ilustrada. En sus textos más íntimos (las memorias, la correspondencia, los diarios) abundan los juicios acerca de la penosa educación recibida por él mismo y por sus compatriotas. Pero, además, escribió algunos ensayos sobre la educación, como El Síndico Personero.

Por otro lado, en Viera y Clavijo es característica la frecuencia con la que utilizó estructuras discursivas características de la literatura pedagógica, revitalizadas y recreadas sobre moldes antiguos en la época de la Ilustración: el diccionario y el diálogo (Galván, 2005, 2009). Y esta estructura es característica, precisamente, de la literatura de este carácter propuesta por Comenius en su Didactica Magna y ampliamente cultivada en el Siglo de las Luces.

Sabemos que Viera escribió para la instrucción de un único niño, el "Excmo. Sr. D. Francisco de Silva, marqués del Viso, hijo único de aquel prócer” [Don José Joaquín de Silva y Sarmiento, marqués de Santa Cruz], en 1771, cuando su discípulo tenía 15 años (y Viera 40), estas seis obras: Idea de una buena lógica; Compendio de la ética o filosofía moral; Nociones de cronología, épocas, eras, lustros, lunaciones, etc.; Epitome de la historia romana; De la historia de España y De la historia eclesiástica (Viera, 2002a: 69). Viera y Clavijo había pasado a ser el instructor del primogénito del marqués de Santa Cruz en 1770, en sustitución de su anterior ayo, el también canario Agustín Ricardo Madan, y continuó siéndolo hasta la muerte de su alumno, en Valencia en 1779. Si bien no tenemos noticia del paradero de estos textos, que quizá se encuentren perdidos, podemos imaginar que se trataría de obras parecidas a otras de similar factura que se han conservado, es decir, obras de carácter didáctico, a la manera de los actuales libros de texto, en los que se aligeraba la materia de estudio con un lenguaje comprensible y adaptado a las capacidades del alumno. Al menos dos de estas obras, la Idea de una buena lógica y De la historia eclesiástica, por cuanto nos indica Viera y Clavijo, estaban escritas en forma de diálogo. Quizá un antecedente de este tipo de obras fuera La dama moralista, o Suma teológica moral, relacionada en sus memorias como una de las primeras que escribió y que, según puede deducirse de esta parca apostilla: "acomodada al estudio de una señora", debió ser obra destinada a la lectura por parte de una sola persona.

Atención aparte merecen sus obras para niños y jóvenes, de carácter instructivo o literario, entre las que podemos contar, nuevamente, como en los casos anteriores, obras originales del propio Viera y Clavijo o traducciones de obras francesas. En esta última faceta hay que encuadrar, además de sus cuentos para niños, los textos de divulgación científica y práctica para niños y jóvenes: en sus últimos años de vida, ya retirado en Las Palmas de Gran Canaria, como arcediano de Fuerteventura, escribiría Noticias de la tierra o Geografía para niños (1807) y Noticias del cielo o Astronomía para 
niños (1807), además de estas otras obras: Librito de la Doctrina Rural (1807); Tratado sobre la Barrilla dispuesto en forma de diálogo (1810); Las preguntas de un curioso, con las respuestas de un amigo, sobre fumigaciones (1812), que guardan una clara relación con los objetivos de las sociedades económicas: la extensión de la educación y la modernización de la industria y las artes técnicas (Galván, 2005: XXXVII).

Negrín Fajardo ha señalado, en distintos trabajos, la modernidad del pensamiento pedagógico de Viera y Clavijo: la necesidad de los estudios secundarios, que no han de ser un simple adorno, sino de extensión obligatoria; la experimentación como forma de aprendizaje; el estudio de la gramática española y no solo de la latina; la necesidad de formación de padres y maestros; el cultivo de la elocuencia, que no ha de confundirse con la retórica, y la consideración de la enseñanza como un juego:

[...] dos cosas debe encargar V. S. al maestro con mucho cuidado. La primera, que no presente desde luego la lectura a los nińos como un trabajo serio, pues ciertamente su edad no sufre estas formalidades; y la otra, que no se enfade con ellos ni los castigue, aunque vea que no hacen unos progresos rápidos (Negrín Fajardo, 1993).

Según Manuel Hernández (2002: 27-28), las ideas del ilustrado canario sobre la educación se concretan en la labor difusora, y no solo de la ciencia, de la que el Diccionario de Historia Natural de las Islas Canarias es la pieza más contundente, sino también de las artes y oficios prácticos (como se aprecia en las memorias para la Sociedad Económica o, especialmente, en el Librito de la Doctrina Rural), en consonancia con la dignificación que la Enciclopedia les otorgaba. Viera tenía una "fe ciega en la felicidad obtenida a través del conocimiento y la educación, la única vía posible para superar las viejas y anquilosadas estructuras" (Galván, 2005: XXVII-XXVIII).

\section{La traducción, instrumento al servicio de un proyecto educativo y modernizador}

Berquin tiene una concepción de la traducción muy común en la época (que también comparte Viera y Clavijo): los letrados del siglo XVIII, instruidos en la escuela de la traducción, de la amplificación y la imitación, utilizaron textos en función de su sensibilidad, de sus necesidades, de su proyecto. Los franceses contemporáneos de Berquin siempre lo consideraron como autor de sus obras, responsable del contenido y de la forma y nadie le reprochó haberse inspirado en textos extranjeros en su época; de hecho, el autor no oculta sus fuentes (Lhérété, 1985; Nières-Chevrel, 2014: 808).

Que para Viera y Clavijo la lectura de los sabios extranjeros era una necesidad y, por tanto, un deber ético su difusión, estudio y, en su caso, traducción, es una realidad tan evidente que no hay más que recordar las palabras de Viera en sus Memorias, cuando habla del fogonazo que supuso, en sus primeros años, el descubrimiento de las obras de Feijoo, que explica con estas palabras:

[...] y al paso que las iba leyendo, o más bien devorando, se iba 
presentando a su razón otro nuevo mundo científico, y a su espíritu otros inmensos horizontes. Así fueron estas como las primeras semillas de cultura y de literatura sensata, porque sin pérdida de tiempo se aplicó a traducir el inglés, francés e italiano, con algunas nociones del griego, cuyos libros, instruyéndolo, desenganándolo y divirtiéndolo, lo hicieron vivir en el siglo de las luces en que muchos no viven (Viera, 2012: 53-54).

Estas palabras de Viera lo alinean con Feijoo, fray Martín Sarmiento o Cadalso, que consideran la traducción como un oficio pero, también, como una necesidad para el enriquecimiento de la cultura y la lengua españolas, jamás una agresión a la cultura y la lengua de llegada (Ruiz Casanova, 2018: 375).

\section{Los resultados de la comparación: la traducción de Viera}

\subsection{Títulos y nombres propios}

Titulos. Viera no hace grandes cambios en la traducción de los títulos, lo cual facilita la localización de la fuente, incluso en aquellos cuentos de Berquin que se identifican con los nombres propios de sus personajes: "Amand > "Amador"; "Caroline " > "Carlota"; "Philippine et Maximin " > "Felipa y Maximino"3. Hay, sin embargo, algunos casos dignos de ser comentados, y guardan estrecha correspondencia con los procedimientos fundamentales usados por Viera para traducir los cuentos de Berquin: la atenuación y la simplificación (en la que se observa una tendencia a la sobriedad y la subordinación al propósito utilitario), la reducción (abreviación del texto original) y la sustitución.

Un ejemplo de atenuación es el de la sustitución del título « Les douceurs du travail " por el más neutro "El gusto de trabajar". Algunos ejemplos de abreviación están en consonancia con la clara tendencia a la reducción por parte del traductor: "La perruque, le gigot, les lanternes, les sacs d'avoine et les échasses " ("La peluca y los zancos"), "Le désordre et la malpropreté " ("El desaliño"), "Le menteur corrigé par lui-même " (“El mentiroso"), "Le rosier à cent feuilles et le genêt d'Espagne " ("El rosal de Alejandría”). En algún otro caso, esta reducción parece estar relacionada con una religiosidad de muy distinto signo, como en el cuento « Si les hommes ne te voient pas, Dieu te voit » que resulta mucho más admonitorio y atemorizador en el

\footnotetext{
${ }^{3}$ Para no hacer farragosa la lectura, hemos optado por indicar tan sólo el título del cuento en español. En el epígrafe "Textos mencionados", antes de la lista de referencias final, el lector dispone de una tabla con la correspondencia entre los títulos de la traducción española y el original francés, pues la escasa extensión de los cuentos facilitará la localización de los pasajes; añadimos también en dicha lista la página en la que comienza el texto en la edición que hemos utilizado para el cotejo, el volumen impreso (completados con las páginas manuscritas de Pereira Pacheco que suplen las que faltan al ejemplar) que se encuentra en el Fondo Antiguo de la Biblioteca de la Universidad de La Laguna (Viera, 1803). Modernizamos ortografía y puntuación en las citas recogidas.
} 
título español: "Dios siempre te ve", aunque, por contrapartida, no en este otro ejemplo: "L'amour de Dieu et de ses parents " > "La piedad filial".

Finalmente, un ejemplo de sustitución es el desplazamiento de atención o énfasis que va desde la simple referencia a la protagonista del cuento en el original ( Euphrasie ») hasta la del juguete al que esta intenta enseńar los afectados ademanes en boga ("La muñeca").

Nombres propios. En general, Viera no sigue la costumbre contemporánea de españolizar a ultranza los nombres, sino que en las más de las ocasiones busca un equivalente casi perfecto en castellano. A los ejemplos anteriores, en los que el nombre del protagonista da nombre al cuento, podríamos añadir muchísimos otros: Denise-Dionisia, Antonin-Antonino, Clémentine-Clementina, Madelon-Magdalena, Helene-Elena, todos ellos en el cuento "La piedad filial"; Alexis-Alejos en "El contratiempo útil"; Robert-Ruperto, en "El nido de pájaros", Euphrasie-Eufrasia ("La muñeca").

Esta proximidad favorece que en la traducción se establezcan parecidas resonancias a las que Berquin parece haber buscado intencionalmente en algunos cuentos donde los nombres elegidos tienen una clara intención semántica (Florencio-Le petit Fleuri, en "Las cuatro estaciones"; Amand-Amador, en el cuento del mismo título). Alguna variante, incluso, mantiene al menos parecida significación etimológica: Teophile-Timoteo. Asimismo, Viera respeta también las fórmulas hipocorísticas, tan apropiadas al lenguaje familiar y coloquial característico del estilo de Berquin y tan bien recreado por el ilustrado canario: Marianita, Luisita, Felipita, Juanita, Frasquito, Gasparito, Pablito.

Alguna vez la traducción de los nombres propios se aleja algo más del original, pero quizá en casos en los que no se encuentra un equivalente inmediato para el antropónimo francés: así, la "Fanchette » o «Fanchonnette » de " Le petit frère » se convertirá en "Juana” o "Juanita" en "La cordera” y "Marianita" en la traducción de Viera que lleva por título "El hermanito" -si bien el manuscrito al parecer autógrafo editado por Acosta Tejera y Aguiar Bobet refleja alguna vacilación, pues la propuesta inicial para el personaje era "Panchita" - (Viera y Clavijo, 2013: 75). Encontramos algún otro ejemplo de evidente domesticación en la Mariquita Pepa o María Pepa (Joséphine, en el original) del cuento "El canario" o en la Dorotea (Henriette) de "El espíritu de contradicción”.

Los nombres dados por los niños a animales de compañía y a juguetes también suelen ser muy próximos y hasta idénticos: el canario Mimí o la muñeca doña Columbina ( Mimi » $\mathrm{y}$ "Columbine », en el texto original, "Le serin », que Viera titula "El canario"), la ovejita Bebé (Bebé, en "La cordera”), el perro Mogol ("Médor », en el original). Un cambio especialmente llamativo es el del hermoso pero irascible perrito "Charmant ", que permite a Berquin el juego antitético del título «Fi ! Le vilain Charmant!» y Viera traduce como "Almíbar", con total libertad, pero con 
gran fidelidad, en realidad, al estilo del original, en el cuento que lleva por título “¿Quita allá tu Almíbar rabioso!”.

Dicho esto, en la obra de Berquin los protagonistas infantiles y algunos sirvientes son mencionados solo con un nombre, mientras que los apellidos singularizan a los adultos -padres y madres, preceptores y ayas, criados y otros personajes-, y lo más frecuente es que se haya utilizado para ello patronímicos reales y, por añadidura, muy comunes en la época, efecto que incide claramente en la verosimilitud del relato, que propone el cuento como si de un caso real se tratara, mientras que son escasísimas las ocasiones, al menos en los cuentos sobre los que Viera trabaja, en las que la referencia sea al oficio o condición del adulto: "le médecin" ("el médico", en el cuento "Amador"), " un pauvre paysan » (“cierto pobre paisano", en "La cordera").

En la traducción de Viera se aprecian, en este aspecto, unas evidentes estrategias de adecuación a la cultura meta al haberse buscado patronímicos españoles igualmente comunes. Llama la atención, incluso, cómo Viera se esforzó en encontrar nombres o apellidos equivalentes (Beltrán-Bertrand, en "Amador") o que al menos mantuvieran cierta proximidad semántica o fonética: M. d’Ogéres > señor de Ojeda ("Los zarzales”), « le gros Thomas " > "Tomás el gordo" (“Clementina y Magdalena”), Mathurin > Matute ("La vid", aunque el mismo personaje es llamado Juan de Mata en "El arrendador"), M. Dorval > barón del Dorado, le vieux Champagne > Campos el viejo ("El criado antiguo"), M. de Valbonne > Francisco Valbuena ("Dionisia y Antonino"), M. de Tourville > señor de Valvilla ("La gallina"), Monsieur Dublanc > don Domingo Blanco ("El arrendatario"), Mme de Monval > doña Ana del Valle ("La avecita de Dios"). Tan solo en un caso el apellido de un adulto no se altera en absoluto, pero sin que ello deba ser considerado un error, pues era costumbre de la sociedad española de aquella época el contratar a maestros franceses para enseñar música y danza y, por ello, sin que haya causado extrañeza alguna, Viera indica que el perrito "danza cualquier minuet tan bien como monsieur Rigodon” («M. Rigaudon », en el original).

La imposibilidad de encontrar un equivalente o un patronímico más o menos cercano quizá sea la razón de que Viera haya propuesto un apellido que resultara tan familiar en España como lo sería en Francia el de la colección de Berquin, aunque a veces produciéndose algún cambio en oficio o posición social de difícil explicación. No hay que descartar la posibilidad de que Viera haya aprovechado tal circunstancia para honrar o mencionar a alguna personalidad relevante de la época: Mme de Cerni > doña Catalina de Castro ("Felipa y Maximino"), M. de Surgy > conde de Nubia ("La vid"), Monsieur de la Ferrière > don Pedro Fernández ("Dios siempre te ve"), les demoiselles Saint-Aubin > las de doña Fausta, M. d'Orville > doctor Urbano ("La fisonomía"), M. Sage > don Policarpo ("Nuestro gran jardín”), M. de Fréville > don Félix González (“La peluca y los zancos”).

Otras veces, Viera opta por convertir el patronímico francés usado por Ber- 
quin en una simple referencia al oficio o condición del adulto. Algunos ejemplos de ello los comentamos en el apartado 4.4.2., "Eliminación de referencias al mundo conocido por el lector de la obra de partida".

\subsection{Sustituciones}

En este apartado daremos cuenta de algunas transformaciones -la mayor parte de ellas, menores o achacables a las necesidades de la traducción- realizadas al traducir los cuentos originales, tal y como aparecieron en L'Ami des enfants, sin mencionar los cambios de modo y tiempo verbal que no nos parezcan especialmente significativos, de los que vamos a poner tan solo dos ejemplos: "Oh! ce ne seraient pas les premiers qu'il aurait croqués tout vifs $»^{4}>$ "no serán estos los primeros que mi gato se ha tragado vivos" (“La nieve”, Viera, 1803); «trouvaient » > "encontraron" ("Las cuatro estaciones"). Ciertamente, estos cambios menores pueden añadir algunos matices incluso representativos de la manera de describir en cada uno de los autores: en el primero de los ejemplos, quizá la sustitución del condicional por el futuro haya potenciado la crudeza de la descripción; en el segundo caso, el pretérito imperfecto permite a Berquin subrayar el carácter cíclico del paisaje, mientras que, con el indefinido, Viera parece privilegiar el punto de vista y la actuación de los personajes.

Para el catálogo de modificaciones por sustitución que presentamos ahora, hemos agrupado los cambios observados en nuestro análisis comparativo, agrupándolos en torno a las posibles coordenadas culturales y estéticas que rigen sobre la sensibilidad literaria y la ideología del traductor español.

\subsubsection{Cambios menores de difícil explicación}

En este apartado consignamos algunos cambios significativos a los que no encontramos aún una función precisa, por lo que podría tratarse, simplemente, de distracciones del traductor, como la de convertir las semanas en "meses": "Il s'était déjà écoulé près de six semaines..." > "Habiéndose pasado seis meses..." ("La niña regañona”); prímula ("auricule») en "anémona” ("Las cuatro estaciones”) o pañuelos en "delantales" ("El nido de pájaros").

También contemplamos aquí cambios relacionados con las circunstancias que singularizan a algún personaje, como la clase social, que podrían deberse a distracciones, como las anteriores, o quizá a otro propósito no tan evidente: así, un « riche laboureur" se convierte en un "labrador pobre" ("Los dos manzanos") o la identificación del adulto que razona con el niño pasa de ser «Le precepteur» a "el padre" ("El nido de pájaros").

\subsubsection{Sustituciones debidas a la adaptación al contexto cultural}

En este apartado agrupamos una serie de cambios explicables en la necesaria

\footnotetext{
${ }^{4}$ Para la transcripción de los textos franceses, modernizamos ortografía y puntuación y actualizamos las formas gramaticales: trouvoient $>$ trouvaient, por ejemplo.
} 
adaptación al contexto cultural de referencias que poseen los lectores españoles, especialmente los infantiles, a los que hubieran causado una gran extrañeza algunas fórmulas de tratamiento (pues los vocativos usados para dirigirse al padre o al hijo pueden haber variado, y así «oui, mon ami » se traduce como "sí, hijo mío" en "Dios siempre te ve") o costumbres o juegos no muy conocidos. Viera, que parece conocer bien los juegos cortesanos e infantiles, los traduce impecablemente: "colinmaillard » > la "gallinita ciega" ("El canario"), « château des cartes " > "casitas de naipes", o incluso "à broche-en-cul », ese antiguo e inapropiado juego infantil adoptado por la corte francesa y traído a la española por los borbones que complacía a Luisa Isabel de Orleáns, la reina consorte de Luis I, según relataba el mariscal Tessé (VallejoNágera, 2006: 418) y que Viera traduce como "la maza de papel en el trasero" ( "Los muchachos que hacen su gusto"). Otras veces, sin embargo, Viera prefiere buscar un referente cultural más cercano, por lo que jugar a "la chasse à la biche » se convierte en jugar al "torito" en "Los muchachos que hacen su gusto".

En todo caso, dado el notable afrancesamiento de la sociedad española, especialmente en el caso de las familias pudientes, muchas palabras no requieren de traducción, como es el caso de algunos hábitos culinarios y enológicos: «fricassée » > "fricasé" ("La cordera"), en los que a veces parece verse algún rastro de las debilidades catadoras del ilustrado canario, como en ese " muscat " que Viera traduce justamente como "moscatel” pero al que añade, a su descripción ("liqueur délicieuse ») la precisión "licor [...] de Frontignac" ("La vid").

En otros muchos casos, las acomodaciones realizadas por Viera son más que pertinentes, aunque siempre con su característica tendencia a la abreviación: "chansons qu'elle avoit apprises des petits bergers d'alentour" > "seguidillas" ("Clementina y Magdalena”); "des airs de sarabandes et de toutes les chansons nouvelles del l'ancient temps " > "la zarabanda y las folías, aires todos que habían sido nuevos había un siglo" ("El almuerzo").

Otras veces, son las expresiones idiomáticas españolas las que se imponen, en la lengua del traductor: "A ces mots, un torrent de larmes coula sur les joues de Joséphine" > "No pudo proseguir porque María Pepa, llorando como una Magdalena..." ("El canario"). Y otras veces la impronta cultista que penetró largamente en la literatura española (poesía, prosa, oratoria del púlpito) del XVIII es la que parece explicar algún giro de regusto barroco el de que cierto "liqueur délicieuse » se haya convertido en un "licor melifluo" ("La vid").

\subsection{Adiciones, precisiones y amplificaciones}

Si bien la labor traductora de Viera, al menos en el caso del único testimonio conservado de su El amigo de los niños, no se caracteriza por la amplificación, sino, antes bien, por la sistemática reducción, simplificación y atenuación del original, encontramos algunos ejemplos en los que el ilustrado canario añade algún detalle o referencia inexistente en el original. 


\subsubsection{Adición de precisiones}

Quizá una cierta indefinición en el texto original sea, para Viera, pero solo en contadas ocasiones, una invitación para añadir algún detalle que introduzca verosimilitud, como en el ya citado "licor melifluo de Frontignac", pero hay otros ejemplos de este tipo y, así, "un beau jour d'été » puede convertirse en "un hermoso día de junio" ("Dionisia y Antonino") o una indicación imprecisa (aunque, en realidad, como veremos, es el procedimiento inverso, el de renunciar a las precisiones, el más frecuente en Viera).

En algún caso, estas precisiones por parte del ilustrado canario quizá busquen potenciar la identificación con el lector, como la estructura comparativa que se añade en la expresión "lloraba como un niño"("Amador").

En otras ocasiones, Viera añade alguna didascalia inicial en los textos enteramente dialogados, dado que algunos textos de Berquin se inician, directamente, con el elenco de los dramatis personae y la primera intervención, como ocurre en « Le vieux Champagne", pero Viera introduce el texto con esta didascalia: "Pablito, hijo del barón del Dorado, estando hablando un día con su padre, le dijo..." ("El criado antiguo"). Igualmente, en "El gusto de trabajar", Viera añade este contexto: "Preguntaba un día cierta señora a su hija, todavía de tiernos años..."; en "La muñeca", la didascalia "Euphrasie (à sa poupée) » queda reformulada en esta situación preparatoria: "Eufrasia estaba un día sola con su muñeca y, teniéndola entre las manos, le decía...".

\subsubsection{Amplificaciones para potenciar el efecto didáctico y moral o para intensificar la presencia de Dios}

Pero, sin duda, las razones más evidentes que mueven a Viera en los escasísimos ejemplos de amplificación sean las determinadas por su ideología, destinadas, bien a potenciar el efecto didáctico y moral, como en estos ejemplos del cuento "Dionisia y Antonino": "Vous êtes tous deux mes bien-aimés, et vous viendrez tous deux avec moi » > "Yo os quiero y os estimo a ambos como a niños virtuosos y ambos vendréis a divertiros conmigo, pues lo merecéis") o del cuento "La piedad filial": " Hélène et Théophile gardèrent le silence " > "A esta maternal reconvención, no respondieron los dos chicos sino con un humilde silencio".

La segunda de las razones de la amplificación tiene sin duda la intención de intensificar la presencia de Dios y representa, por tanto, una interesante divergencia entre las obras de Berquin y de Viera: "Ah! je voudrais bien qu'il [l'hiver] restât en chemin " / Permita Dios que se le rompan las piernas al invierno y no pueda llegar" ("Las cuatro estaciones").

\subsection{Supresiones, atenuaciones, simplificaciones y abreviaciones}

Los cuentos traducidos se caracterizan, antes que nada, por ser adaptaciones mucho más breves que las obras de partida, como veremos, pero el hábito de simplificar es sistemático y hemos creído ver algunas claves o constantes para interpretar sus porqués. 
Ciertas supresiones o simplificaciones, en la traducción española, podrían explicarse, como algunas de las sustituciones anteriormente analizadas, por las diferencias culturales entre las sociedades francesa y española, siendo las más llamativas las que se refieren a la efusión en la expresión de los sentimientos y las emociones. Por último, otros de los cambios agrupados en este apartado guardan relación con las diferentes propuestas educativas de Berquin y Viera, pareciendo ser la de este último más directa y unidireccional que la del aquel. Pero, en general, parece percibirse en todo este apartado una actitud, con motivaciones y consecuencias en el estilo pero también en la propuesta pedagógica, mucho más práctica y utilitarista en el ilustrado canario.

\subsubsection{Eliminación de referencias al mundo conocido por el lector de la obra de par- tida}

Algunas, pero significativas, simplificaciones pueden deberse, tan solo, a estrategias usadas por un experto y competente traductor, buen conocedor de las lenguas de partida y de llegada: "son esprit était vif et pénétrant" > "claridad de entendimiento"; "son imagination forte et sensible » > "viveza de imaginación"; «lui conciliait tous les cœurs » > "se robaba los corazones" ("La cicatriz").

Sin embargo, otras simplificaciones y supresiones entran decididamente en las estrategias de acomodación al mundo referencial del lector meta. En relación con este último aspecto, Viera pudo haber utilizado las estrategias de la sustitución de referencias geográficas, gentilicias, patronímicas o antroponímicas por equivalentes castellanos, pero parece haber preferido en mayor grado eliminarlas a favor de una marca genérica o un hiperónimo, como en estos otros ejemplos: "Mme de Sauseuil» > "cierta señora” ("El gusto de trabajar"); «M. D’Orsay» > "El padre” ("Los muchachos que hacen su gusto"); "Mme de Cellières » / "La madre" ("El espíritu de contradicción"); "Jacquot » > "el muchacho" ("La nieve").

\subsubsection{Supresión de precisiones y descripciones}

Otras supresiones, en cambio, alejan la propuesta estilística del canario de la muy conocida tendencia al sensualismo y la descripción por parte del burdigalés y, por ello, han de relacionarse con el apartado que denominamos atenuaciones o mitigaciones.

Como ejemplos de una simplificación (atenuación, en realidad) del estilo de Berquin, podemos incluir la renuncia a reproducir imágenes y figuras literarias: por ejemplo, la personificación que otorga un papel activo al cielo y al barómetro, en el cuento "El contratiempo útil”, que quizá habrá parecido innecesaria a Viera: «Le ciel et le baromètre s'accordaient à parler contre lui ».

Podemos incluir muchos otros ejemplos de supresión de precisiones, unas de carácter menor, como, en el cuento "La nieve", el número de pájaros que vende el chico ( il y en a dix-huit») o el tiempo transcurrido ( Enfin la neige se fondit...»), otras más sistemáticas y drásticas, que eliminan enumeraciones presentes en el origi- 
nal, como las frutas ( i ils mangèrent des cerises, des fraises et d'autres fruits de la saison " > "Comieron cerezas y demás frutas del tiempo", en el cuento "Las cuatro estaciones") o las especies de pájaros o las maneras en las que estos buscan alimento, como ocurre en el cuento « La neige »:

Des troupes nombreuses de moineaux, de linottes, de pinsons et d'alouettes, s'abattaient dans les chemins et dans les cours des maisons, et furetaient des pattes et du bec dans les amas de débris, afin d'y trouver quelque nourriture [...]

Y que queda abreviado de esta manera en la versión de Viera: "Veíaseles volar a refugiarse en los pueblos para hallar socorro en los hombres, y una bandada de gorriones y calandrias se posaban en los caminos y corrales de las casas, escarbándolo todo para encontrar algún alimento" ("La nieve”).

\subsubsection{Supresión de didascalias, apartes en el diálogo y acciones}

Las supresiones de frases del texto original afectan a múltiples aspectos característicos en los textos de Berquin: por ejemplo, a las didascalias o apartes en los textos con estructura dialógica o dramática, que desaparecen del todo en muchas ocasiones, a los apartes y a determinadas acciones que al canario deben haber parecido poco importantes y pueden estar relacionados con los aspectos que comentaremos en los apartados siguientes en relación con la drástica reducción del diálogo. Por ejemplo, Viera elimina explicaciones con valor de didascalia como las siguientes: «Ils présentent chacun leur main avec un oiseau plumé " ("El nido de pájaros"); "se leva en frappant dans ses mains" ("El canario").

\subsubsection{Simplificación del mensaje moral}

Son frecuentes, en Viera, los ejemplos de reducción de las digresiones de carácter moral en favor de una simplificación del mensaje, como vemos en estos ejemplos: "Nous sommes heureux de ce qu'il n'est pas en notre pouvoir de régler le cours de la nature. Tout serait perdu pour notre bonheur, si nos vœux téméraires étaient exaucés " > "Tengámonos por muy dichosos de que no dependa de nosotros el arreglo del universo, pues entonces todo lo malograríamos" ("Las cuatro estaciones"); «Entends-tu, mon Dieu? Nous voulons aussi faire tout ce qui est dans tes commandements ", frase eliminada en la traducción española, lo cual disminuye el carácter voluntarioso y ejemplar de los niños ("La piedad filial”); "Rends-nous bons, justes et sages " > "Haznos buenos" ("La piedad filial").

\subsubsection{Un tipo de simplificación: la atenuación o mitigación}

Preferimos considerar como una estrategia aparte, al menos en cuanto a los efectos que produce sobre la obra, la sistemática atenuación o mitigación, que es otro de los signos distintivos de esta traducción de Viera y que afecta a múltiples aspectos y parece obedecer a razones también diversas:

a) La omisión de detalles en la enseñanza o el castigo recibido, como en el 
cuento en que Viera eliminó los detalles de la escena en la que se ve al padre y a la hija comiendo la fruta regalada por Mathurin mientras son observados con gula y enorme frustración por los hermanos castigados ("El arrendatario").

b) La atenuación en la descripción de la fealdad: "Sa figure, sans être d'une laideur repoussante, ne répondait point la beauté de son âme" > "Sin ser tan fea que espantase, era sin duda mucho más linda en el alma que en el cuerpo" ("Felipa y Maximino").

c) La omisión o atenuación de la descripción de cualidades morales y sus efectos, tendencia de la que espigamos algunos ejemplos: " une âme pleine de noblesse et de générosité " > "dotado de nobleza de alma"; "son humeur franche et joyeuse " > "igualdad y alegría de humor" ("La cicatriz").

d) La mitigación del estilo descriptivo, más redundante pero mucho más sensual y lírico de Berquin: "en respirant leur parfum, et en admirant leur fraîcheur et leur éclat" > "gran deleite con el suave olor y viveza de los colores"; " un vent léger faisait rouler en ondes comme une mer doucement agitée " > "azotadas de un viento suave, formaban unas ondas apacibles"; "s'ébattre dans les champs" > "holgándose"; "des arbres courbaient sous le poids des plus beaux fruits" > "todos los árboles estaban cargados de fruta" ("Las cuatro estaciones"); " la terre tout autour, afin qu'elle pût se pénétrer plus facilement des feux du soleil et de l'humidité de la rosée " > "a fin de que las raíces prosperasen" ("Los dos manzanos"); "Ses plumes étaient hérissées, et il paraissait rond comme un peloton", frase que Viera suprime en el cuento "El canario"; "¡Voyez ces belles grappes; les unes violettes, les autres toutes noires!" > “Qué color de racimos!" (“La vid”); « le sang coulait à grands flots de ses tempes » > "copiosa” ("La cicatriz").

Un tipo muy revelador, a nuestro juicio, dentro de los ejemplos de atenuación o mitigación, son los que afectan a la expresión de las emociones, y que parecen deberse a razones de cambio de gusto (relacionados, por tanto, con los ejemplos de las líneas antecedentes, y claves para establecer algunas diferencias entre el Neoclasicismo francés y el español) pero también, al mismo tiempo, a razones culturales:

a) Atenuaciones que mitigan los estados de ánimo, las demostraciones de cariño y la expresión de las emociones: "Hélène et Théophile ... embrassèrent plus tendrement que jamais leur maman " > "acompañado de apretados abrazos a su madre" ("La piedad filial”); "voilà son visage tout bouleversé " > "la criatura llora"; «avec empressement" > “con curiosidad" ("El hermanito"); "Et qu'y a-t-il donc de si pressé? » > “Pues qué ha sucedido? ¿Qué hay de nuevo?” ("El canario”).

b) Eliminación de las expresiones e indicaciones sobre demostraciones afectivas y expresión de las emociones, como las siguientes frases y pasajes, eliminados en la traducción española: « en la serrant tendrement dans ses bras » o el episodio en que la madre, muy emocionada por la respuesta de su hija, se pone a llorar ("La niña regañona"); "le pressa sur son sein " ("La piedad filial”); "lui dit d'une voix étouffée » 
(“La niña regañona”); "Il faudrait être encore à l'âge heureux de Cyprien pour se représenter l'excès de sa joie " ("La gallina”); "Au lieu de songer aux moyens de lui donner des secours, il demeurait couché auprès de lui, en poussant les plus tristes sanglots »; "Le retour de Marcelin à la vie, fit naitre une vive joie dans le coeur de Ferdinand; mais elle ne fut pas assez puissante pour calmer entièrement sa douleur... "; "Ces discours que Marcelin lui adressait sans le voir redoublaient encore la tristesse de Ferdinand " ("La cicatriz"); en este mismo cuento, las palabras pronunciadas por Marcelin en la inconsciencia ("Mon cher Ferdinand, s'écriait-il, que t'ai je donc fait pour que.....pas te fâcher ") quedan reflejadas así en la traducción española: "le nombraba frecuentemente cuando deliraba".

\subsection{Los cambios más significativos: la simplificación del proceso de reflexión}

La reducción es, evidentemente, mucho más frecuente y sistemática que la sustitución y la amplificación, si juzgamos por los ejemplos traídos hasta ahora. Ahora veremos cómo la reducción no solo adquiere la forma de la eliminación puntual de alguna frase o precisión o la forma de la simplificación o la atenuación o mitigación, sino que llega al nivel de la abreviación drástica del original, del que pueden llegar a desaparecer párrafos y aun páginas completas, en beneficio de una abreviación sistemática que, a nuestro juicio, tienen evidentes consecuencias en la propuesta pedagógica resultante, pues puede afectar, en primer lugar, a las fases del aprendizaje, tanto en los estadios previos a la comprensión de los propios errores como en la reflexión y verbalización por parte del aprendiz, máxime teniendo en cuenta que el proyecto original de Berquin está centrado en el desarrollo de la expresión oral.

\subsubsection{El proceso de comprensión del error moral}

a) Eliminación de circunstancias y acciones que describen los estadios previos al aprendizaje. Por ejemplo, Viera omite precisiones, en su traducción del cuento « La neige ", acerca del gran número de pájaros o las exclamaciones y la descripción de la emoción de Luisa cuando cuida de estos, imprescindibles para entender mejor cómo la niña acaba por olvidar sus muñecas.

b) Omisión de las motivaciones y caracterización previa de los personajes. Pongamos algunos ejemplos: En "Felipa y Maximino", Viera elimina la referencia a la muerte del padre ("surtout depuis la mort de son père »), causa probable de la actitud de la madre, disminuyendo la empatía hacia esta figura en el lector. Igualmente, omite el pasaje en que Berquin explica por qué Philippine cuida tanto a su madre: "qui, dans les regards éteints et les traits abattus de sa maman, croyait voir un adoucissement de sa rigueur accoutumée ", dato importante que informa al lector del doloroso error de apreciación de la niña.

En "La nieve", Viera olvida explicar la razón por la que los pájaros no encuentran comida: "Louise en fut attristée. Les petits oiseaux le paraissaient bien davantage. Comme toute la terre était couverte à une grande épaisseur, ils ne pouvaient trou- 
ver aucun grain, aucun vermisseau pour apaiser leur faim » > "Luisa se puso triste, $y$ los pajaritos mucho más, porque no hallaban ni grano ni orugas que comer".

En "El contratiempo útil", precisiones como «Il s'était levé de très bonne heure, contre son ordinaire, pour hâter les préparatifs de l'expédition » contribuyen a subrayar el estado de ánimo de Alexis, su deseo de salir, precisión que Viera habrá considerado inútil desde un punto de vista narrativo.

En "El nido de pájaros", Viera omite la traducción de «Ce n’est pas en effet par un instinct de cruauté, mais seulement par un défaut de réflexion, que Robert avait commis ces meurtres".

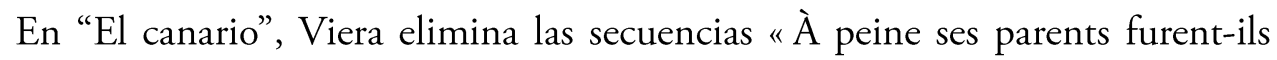
entrés [...] tout ce qui lui était nécessaire » $\mathrm{y}$ «Le lendemain, dès la pointe du jour [...] quelle se fit conduire chez ces Demoiselles ", que ilustran la inconstancia de la niña y participan por tanto de la demostración expuesta por Berquin.

En "El arrendatario", Viera omite traducir la descripción de la maldad del hijo ( " Il appela ensuite un domestique, et lui de balayer les ordures que Mathurin avait répandues sur le parquet avec ses souliers ferrés ») o los múltiples detalles que demuestran la bondad y honestidad del trabajador (el diálogo entre este y el padre que muestran cuán penoso es el trabajo y cuánta su honestidad, la invitación a los hijos de M. Dublanc, así como sus buenos deseos para con los niños, las palabras del padre que lo animan para su tan duro trabajo: "forces pour ses rudes travaux" y deseando una buena salud para su familia: "de la santé pour sa famille»), en una función contrapuntística evidente: poner de relieve la bondad, la generosidad y la valentía de Mathurin, o la muy diferente actitud de la niña, que contrastan con la maldad gratuita del hijo. Igualmente, Viera resume las palabras elogiosas del padre sobre su otra hija, Sophie: "Je vois, dit-il en la baisant du front, que ma Sophie sait comment on doit se comporter envers d'honnêtes gens " con esta réplica del padre: "Tú sí eres mi hija y no estos infames que se burlan de los hombres de bien"; Viera también acorta significativamente el largo pasaje " Roger et Alexandre se regardèrent en dessous [...] Il est vrai que Claudine s'était surpassée pour les bien traiter", omitiendo las bromas autocensuradas de los hijos y evitando dar detalles sobre los animales que descubren en la granja o sobre la reacción positiva de los niños. Esta parte tiene otra vez, en el original francés, la doble función de contrastar la actitud reprensible de los niños con la generosidad de los granjeros y por consiguiente mostrar cuán erróneos eran los prejuicios de los hijos.

En "La gallina”, tenemos otro caso de simplificación sistemática: en la versión francesa, cinco párrafos permiten al lector entender lo bueno y justo que es el padre de Cyprien, precisar en qué condiciones el hijo recibirá la recompensa prometida por el padre y comprobar cuán serio y estudioso es el hijo que aprueba el examen, lo que provoca la alegría de su padre que lo recompensa regalándole un jardín, aspectos todos que Viera resume en estas breves frases: 
Cipriano, hijo del señor de Valvilla, hacía notables progresos en su educación, por el cuidado que su padre tenía de recompensarle agradablemente. Un día en que había desempeñado con mucho lucimiento sus ejercicios sobre la historia romana, lo llevó consigo al jardín....

En "La nieve", Viera omite ciertas precisiones y la emoción de Luisa cuando cuida a los pájaros, haciendo que este pasaje de Berquin:

Quelle joie pour Louise! Elle courut dans la volièe, ayant son tablier plein de chènevis et de millet. Tous les oiseaux voltigeaient autour d'elle, en regardant leur déjeuner d'un oil d'appétit. Elle descendit ensuite dans la cour et offrit un ample repas aux oiseaux affamés. Elle se voyait alors près de cent pensionnaires qu'elle nourrissait. C'était un plaisir, un plaisir! jamais ses poupées ni ses joujoux ne lui en avaient tant donné.

quede resumido de esta manera: "Ella prosiguió en el cuidado de echarles de comer con tal atención, que casi no hacía caso de sus muñecas y escarapelas" ("La nieve").

Otro ejemplo similar podemos encontrarlo en "El nido de pájaros", donde el traductor español suprime dos párrafos enteros en los que se describe la obstinación de Robert y su crueldad hacia los pájaros ("Cécile qui était l'ainée, se déclara pour [...] elles agitaient tristement leurs ailes »), que quedan reducidos a esta simple frase: “El cruel Ruperto, lejos de compadecerse...”); igualmente, también omite el traductor, en este mismo cuento, qué estaba haciendo Robert cuando llega el preceptor: "Tandis qu'ils se livraient à cet amusement barbare, ils virent de loin venir leur précepteur ", quedando simplificado en "A este tiempo alcanzaron a ver desde lejos a su padre...".

\subsubsection{La amputación del diálogo}

En relación con la sistemática reducción del diálogo, la traducción de Viera muestra interesantes desviaciones en estos aspectos, con cambios llamativos en cuanto a las posturas entre los intervinientes, la adjudicación de las frases a unos o a otros y reflejando, en general, una simplificación y reducción drástica de las frases de adultos y de niños, especialmente las que tienen que ver con el curso de las reflexiones, así como de la descripción de los procesos del aprendizaje moral:

a) Atenuación de la fuerza con la que se defienden las ideas contrarias: «cette proposition fut combattue par Robert » > "pero Ruperto fue de dictamen que..." (“El nido de pájaros").

b) Conversión del estilo directo en indirecto, lo cual contribuye a atenuar la emoción de la niña en el cuento "El hermanito": "Mes chers parents ont pris les mêmes peines pour moi " > "ella se acordaba de que les había costado iguales penas y se mostraba tan reconocida que...”.

c) Atenuación o eliminación de las acciones, los ejemplos traídos al efecto y los argumentos de los preceptores que apelan a la sensibilidad del niño y su poder de 
empatía, sustituyéndolos en ocasiones por preceptos más contundentes. Por ejemplo, para convencer aún más al hijo de su tiranía, el preceptor/padre recurre a una imagen en la versión de Berquin de "La nid de moineaux " : "Ainsi, si ces oiseaux avaient pu s'exprimer en langue humaine, vous les auriez entendus s'écrier: "Ah! [...]" », que Viera zanja con la frase "Así, debes tener entendido que esos pobrecitos decían con corta diferencia...” ("El nido de pájaros").

En el cuento "El canario", Viera eliminó el momento en que M. de Gourcy, emocionado por las demostraciones de arrepentimiento de su hija, le devuelve su canario después de reñirla, secuencia que forma parte de su proceso reflexivo, pues permite que se le dé otra oportunidad sin que la autoridad paterna parezca debilitada: «M. de Gourcy se laissa enfin toucher par les prières de Joséphine, et lui rendit le serin. Ce ne fut pas sans lui faire une réprimande sévère, et des exhortations pressantes pour l'avenir ».

En "La gallina", no se reproduce el ejemplo traído por el padre para convencer a su hijo: "Te serais-tu mis en fureur contre elle, si elle n'avait gratté que dans les orties? Et d'où peut-elle avoir appris à faire une différence entre les orties et les œillets?»).

En el cuento "El nido de pájaros", el traductor español suprime una parte del diálogo, que quizá haya parecido superflua a Viera, entablado entre el hijo y el preceptor («LE PRÉCEPTEUR. Vous savez que je ne vous ai pas interdit [...] quelques malices »), y que anuncia de manera progresiva la lección que va a recibir el hijo: poco a poco, el padre introduce el tema al confirmar que le parece justo que su hijo se divierta para luego enseñarle que divertirse a expensas del otro es un acto injusto.

Finalmente, los más llamativos ejemplos de abreviación afectan a la esencia misma del método socrático propuesto por Berquin en los diálogos entre padre e hijos. Si el método por el progenitor de «Les quatre saisons " requiere que el niño formule sus respuestas tras la lectura de su libreta de memorias y las sistemáticas preguntas de su padre, para que realice luego una recapitulación de los argumentos esgrimidos por el hijo, para que este perciba sus muchas contradicciones, una y otra cosa se eliminan en la traducción de Viera, donde el padre hace directamente la pregunta final a su hijo: “¿Y qué te parece a ti que se infiere de estas contradicciones?” ("Las cuatro estaciones").

En general, Viera prefiere sacrificar el texto original yendo al mensaje central: el resultado de las reflexiones del niño, sin entretenerse en el proceso que lo ha llevado hasta allí. En "El espíritu de contradicción", se produce la omisión de una parte del diálogo entre Henriette y la madre («Ils vont croire que je suis en pénitence.. [...] ta visite »), en la que Berquin muestra cuánto le duele a la hija no poder dar su regalo a su prima. La vemos buscar una solución, que luego propone a su madre y esta le da a entender poco a poco que existe otra solución mejor. Viera omite esta parte para pasar directamente al mensaje moral. También omite la frase de la madre en la que anima a 
su hija valorando su actitud ( Je te connais assez de courage pour prendre un parti ferme, et le soutenir ») y reiterando en la intervención siguiente su confianza en la hija ("Je n'en attendais pas moins de la force de ton caractère »). Viera omite también las frases siguientes que explican el proyecto de la madre ("Eh bien! Si je te vois persister [...] générosité »), así como la réplica de la hija que expresa su alegría y su alivio besando a su madre, también alegre y aliviada. En la versión de Viera, como otros lugares, los progenitores tienen un papel más directivo: aquí es la madre la que pide a su hija le dé un abrazo cuando en el texto de Berquin es la hija quien besa espontáneamente a su madre.

En "La niña regañona”, la respuesta de la hija es mucho más breve que en el cuento original: Viera zanja con la frase "Señora -respondió Rosalía-, pedírselo continuamente a Dios" la reflexión con la que la niña subrayaba su esfuerzo para conseguir cambiar su carácter: "Je m’en suis occupée sans cesse, lui répliqua Rosalie. Il m’en a bien coûté: mais tous les matins et tous les soirs, cent fois dans la journée, je priais Dieu de soutenir mon courage ». En el mismo cuento, Viera suprime un largo episodio final: la niña juega con sus nuevos juguetes y sus amigos y, luego, la madre cuenta su historia a una niña que tenía el mismo defecto y que, a la luz de este testimonio, decide cambiar de actitud, mostrando este cuento que el cambio hizo feliz no solo a Rosalie sino también a cuantos la imitaron, para concluir: "Quel enfant bien né ne voudrait pas jouir de cette gloire et de ce bonheur? ». Este procedimiento retórico que consiste en terminar abriendo el cuento por una pregunta dirigida al niño lector desaparece también en la versión española.

En "La vid", es también llamativa la omisión de las exclamaciones del hijo que admira la belleza de la viña creyendo ingenuamente que su padre cambió el árbol: "Ah! mon papa, dit Julien [...] beau », o la supresión de la frase en la que el niño expresa su deseo de probar la uva para ver si es tan buena como bella y omite, asimismo, el preámbulo a la revelación del padre: «Te voilà tout étonné, mon fils, lui dit M. de Surgy; je te surprendrais bien davantage si je te disais que c'est là cet arbre $[\ldots]^{\prime}$.

En el cuento "La fisonomía”, Viera realizó una llamativa labor de reducción, omitiendo traducir más de tres cuartas partes del cuento de Berquin: la poda afecta, sobre todo, a los turnos del diálogo y a la explicación del itinerario mental seguido por el aprendiz, suprimiendo todos los ejemplos dados por Agathe, algunas de las réplicas gracias a las cuales el padre consigue que su hija se encare con sus propias contradicciones, el pasaje sobre Sócrates y Esopo y la última parte del diálogo en que, poco a poco, el padre logra que la hija deduzca por sí misma la conducta que tiene que adoptar.

Otro ejemplo de drástica reducción del diálogo y también de la narración se encuentra en "El criado antiguo", del que dejan de traducirse las diez páginas finales. En el texto original, el hijo, tras reconocer el error cometido a lo largo de una produc- 
tiva conversación con su padre (mucho más breve en la traducción española), decide ir a pedir excusas al anciano sirviente y cuenta luego al padre lo sucedido y, tras este acto de arrepentimiento, aún prosigue largamente la conversación entre padre e hijo, haciendo que la reflexión moral haya ido desde su aplicación a un caso concreto hasta una enseñanza general que se apuntala con otros consejos sobre cómo tratar a los sirvientes y hasta con una historia intercalada, la de M. de Floré, que contaba a M. Dorval su padre. Viera decidió prescindir de toda esta parte final, pero también de las anteriores réplicas, que subrayan el deseo del hijo de aprender siguiendo los ejemplos de su padre: " je me servirai un jour de vos leçons et de votre exemple [...]. Ah ! mon papa, si cela ne vous importune pas, je serai bien aise d'entendre cette histoire». El padre concibe la transmisión de este recuerdo como una recompensa para el hijo: « Je me fais un plaisir de t'accorder cette récompense de ton repentir et de ta bienfaisance envers l'honnête Champagne ». En este mismo cuento, Viera suprime una parte del diálogo entre el padre y su hijo que Berquin había usado para explicar por qué el miedo al castigo le impide decir la verdad y en la que vemos cuán cariñoso y ecuánime a la vez es el padre («Paulin: Si je vais vous révéler mes fautes [...] / M. Dorval: Tu fais, mon fils, [...] sur mes promesses »).

Ya señalamos entre las adiciones, algunas menciones a la deidad que no se encontraban en el original. Igualmente, son cambios significativos, que dicen mucho acerca de las distintas concepciones de Berquin y de Viera, algunas supresiones del ilustrado canario: por ejemplo, en "La neige ", la madre realiza una comparación entre su hija y Dios ("Quand tu seras plus grande, tu pourras secourir tes semblables, comme tu secours aujourd'hui les oiseaux; et tu ressembleras alors à Dieu bien davantage. Ah! quel bonheur pour l'homme, lorqu'il peut agir comme Dieu!») que Viera suprime en su traducción: "...y te acostumbras a socorrer a tus semejantes, que es la mayor dicha del hombre" ("La nieve").

\section{Conclusiones}

Las traducciones de Viera y Clavijo, siguiendo los criterios establecidos por Savory (1968), reproducen en muchos casos las palabras, las ideas, el estilo del original y la traducción suena incluso como si fuera una obra original, como una obra contemporánea al autor original y al traductor. También observamos que el autor español, al añadir y sobre todo al omitir muchos pasajes de los cuentos de Berquin, se acerca más a lo que Nida (1964: 166-171) llamó una equivalencia dinámica.

En todo caso, las primeras observaciones a la vista de esta comparación nos muestran a un traductor que opera libremente sobre la obra original, como ya hiciera Arnaud Berquin con los textos alemanes, ingleses y holandeses que vierte al francés en su colección L'Ami des enfants. Cuando Viera se ocupa de estos cuentos ya ha realizado una importante labor de traducción, ha establecido prolongados contactos con el mundo cultural francés y se muestra como un traductor avezado y experto que obra 
libremente.

Los mecanismos de traducción de Viera son, pues, en lo esencial, similares a los de Berquin, aunque una comparación entre uno y otro revela interesantes desviaciones. Teniendo en cuenta la tipología sugerida por Urzainqui (1991), los procedimientos de Viera son, preferentemente, los de la traducción-selección, la traduccióncorrección y la traducción-abreviación, aunque de una manera menos rotunda, también pueden encontrarse ejemplos de traducción-nacionalización.

En cuanto a la traducción-selección, hay que tener en cuenta que Viera, como Berquin, opera por reducción, realizando su propia biblioteca tomando como punto de partida la selección de los textos franceses (solo una parte de la publicación de Berquin es vertida al español por Viera, de la misma manera que Berquin compone su colección tomando como punto de partida fuentes alemanas, inglesas y holandesas más extensas), aunque no es fácil de establecer el porqué de la selección realizada por Viera de esos textos de Berquin y no de otros de la colección, ya que la obra original y más completa se ha perdido, y solo contamos con un testimonio que ya es versión incompleta de la traducción original.

La traducción-corrección, por su parte, es muy frecuente en la época y más aún si se trata de obras destinadas a lectores infantiles, como ocurre con la traducción que Iriarte hace del Robinsón de Campe:

En esta misma línea está la traducción de El nuevo Robinsón de Campe hecha por Iriarte (1798), quien, como él mismo confiesa, aun sin apartarse de la sustancia y método del original, se toma la libertad de suprimir, aumentar o alterar no pocos lugares, ya con el fin de corregir equivocaciones, ya con el de aclarar doctrinas difíciles de comprender por un niño, o ya para evitar ciertas repeticiones molestas y algunas digresiones que distraerían del principal asunto (Urzainqui, 1991: 630).

Aunque no todas las sustituciones, amplificaciones o supresiones tienen, en estos Cuentos de niños, el mismo objetivo. En todo caso, sustituciones y amplificaciones, en Viera, son apreciablemente menores en cuanto a su frecuencia y a sus efectos que las reducciones: se dan en menos ocasiones y consisten en la sustitución o adición de alguna palabra o frase, mientras que las reducciones se dan sistemáticamente y pueden llegar a afectar a la supresión de varias páginas.

Las muy contadas sustituciones pueden obedecer a criterios de carácter ideológico -la mencionada categoría de la traducción-corrección (Urzainqui, 1991: 630633)-, o a la existencia de algunas y muy contadas distracciones del traductor pero también puede tratarse de destrezas de un traductor avezado que ha de realizar algunas acomodaciones de carácter cultural (lo que podría englobarse en la categoría de traducción-nacionalización).

La mayor parte de estas sustituciones son achacables a las estrategias de adap- 
tación del texto a una cultura distinta, un tipo de domesticación del texto que es mucho más acusado en la literatura infantil y juvenil y que, según muestra este análisis comparativo, es una característica fundamental en la traducción de la literatura para niños desde su propio nacimiento en el siglo XVIII. En este apartado contemplamos las referencias a juegos infantiles o a fórmulas de tratamiento (especialmente entre niño y adulto), entre otras. Aunque, a la vista del temprano estudio de Cioranescu (1954), las libertades se las permitía Viera con todos los textos literarios que vertió al castellano, una profundización en los métodos de traducción de Viera quizá revele diferencias entre las obras escritas para el público general y las escritas para niños, pero para establecer estas divergencias sería necesario abordar un proyecto comparativo mucho más ambicioso.

Algunos de estos cambios menores parecen obedecer a unos parámetros culturales distintos, que explican la simplificación de precisiones (gentilicios, referencias geográficas que de nada servirían al lector español) en favor de expresiones más genéricas, o la sustitución de algún juego infantil en boga en Francia por otro equivalente que sería conocido por los niños lectores de las traducciones de Viera, o, dado el singular afrancesamiento de la sociedad española, no habrían requerido traducción, existiendo en el habla coloquial galicismos o realidades importadas, como en la gastronomía o, salvando las distancias, la indumentaria.

Las adiciones y amplificaciones pertenecen al grupo de estrategias de traducción menos frecuentadas por Viera y nos muestran una de las más evidentes diferencias entre los proyectos de Berquin y de Viera, pues son frecuentes en Berquin interpolaciones e historias-marco inexistentes en sus fuentes extranjeras que están ausentes entre las técnicas del ilustrado canario, quien tiene tendencia, precisamente, a eliminar las historias y ejemplos traídos al caso. Las escasas amplificaciones y precisiones añadidas por Viera se explican por motivos de eficacia narrativa, añadiendo alguna didascalia para situar mejor una estructura dialogada, o por motivos ideológicos, entrando entonces entre las estrategias de traducción-corrección, más que en las de la traducción-acumulación (Urzainqui, 1991: 629-630).

Entre los escasos ejemplos encontrados -aparte de algunos casos de precisión que no son la solución más frecuentada por Viera- tan solo llaman la atención las destinadas a intensificar el mensaje moral y la presencia de la providencia y presencia divinas, pudiéndose mencionar la presencia divina allí donde el original no la ha invocado o, por el contrario, elimina las comparaciones entre el niño y Dios que su madre hace para animarlo a cuidar de los otros, como en la traducción, ya mencionada, del cuento "La neige ». Evidentemente, estas opciones deben achacarse a las necesidades de la adaptación, a causa de las diferencias evidentes entre la Ilustración francesa, de signo más laico, y su menos arriesgada aclimatación en España, donde precisamente fue impulsada por el clero ilustrado, al que pertenecen Feijoo o Viera y Clavijo. Muchos pasajes de las memorias de Viera (y no tanto de la epistolografía, su lado 
más íntimo y sincero) nos ayudan a reconocer la importancia de actuar con cierta prudencia en ciertos temas.

Pero es, sobre todo, la traducción-abreviación (Urzainqui, 1991: 627-629) la más frecuente de las estrategias usadas por el ilustrado canario, y puede deberse a motivos muy diversos, entre los que no pueden descartarse posibles condicionamientos editoriales, por la modestia de la edición de 1803 ni tampoco razones literarias y pedagógicas, que señalan una tesitura bien distinta que va desde el sensualismo y el ejercicio mayéutico del diálogo entre niño y adulto característicos de la propuesta de Berquin y sus modelos alemanes hasta la sobriedad, la contención y el utilitarismo de Viera.

Entre las simplificaciones menores figuran las que tienen que ver con la eliminación de precisiones cuya traducción domesticada hubiera requerido la referencia a lugares y apellidos españoles y que suelen ser resueltas por Viera con la remisión a figuras menos marcadas, en favor de una indeterminación de signo opuesto a las precisiones de Berquin, que probablemente tenían la intención de dotar de verosimilitud al relato.

Las versiones que Viera y Clavijo realiza de los cuentos para niños de Arnaud Berquin se caracterizan, antes que nada, por ser adaptaciones mucho más breves que las obras de partida, pero el hábito de reducir es sistemático. Si bien algunas simplificaciones muestran la eficacia de un traductor avezado, como la siguiente, en la que la expresión idiomática española elegida podría resumir perfectamente los dos efectos indicados en el original: «achevèrent de ramener la paix et la joie dans son cœur » > "acabaron de volverle el alma al cuerpo" ("El contratiempo útil”), una parte de las simplificaciones realizadas por Viera y Clavijo se explican por una explícita renuncia a la domesticación sustituyendo las referencias geográficas o paisajísticas por posibles correlatos españoles en beneficio de una imprecisión que haga más universal el mensaje.

Efectivamente, las atenuaciones, mitigaciones y supresiones son el procedimiento fundamental en las adaptaciones de Viera y Clavijo: más interesado en el meollo narrativo y didáctico, el ilustrado realejero prefiere eliminar las referencias descriptivas, pero también, en aras de una simplificación sistemática, elimina gran parte de las réplicas en el diálogo o las historias intercaladas que los padres suelen contar a los niños para educarlos. De hecho, en muchos de los cuentos parece existir lo que podríamos llamar una poda sistemática, reduciéndolos drásticamente y dejando de traducir páginas enteras.

En la propuesta pedagógica de Arnaud Berquin, se atiende cuidadosamente al proceso interno que lleva al niño a entender los errores de su comportamiento. En dicho proceso tiene mucho que ver la actitud siempre presente del padre o preceptor que, más que sancionar o castigar sin más el mal comportamiento, intenta que el niño aprenda por sí mismo, a través de la experiencia y la verbalización. El diálogo, 
pues, refleja una concepción socrática de acceso al conocimiento moral: es el niño el que, habitualmente, cae en la cuenta acerca del aprendizaje que debe sacar de la experiencia vivida. En algunos casos, Viera y Clavijo realiza cambios muy significativos en la estructura de la conversación. Los cambios más significativos y que requieren, por tanto, un tratamiento más profundo, afectan a aspectos cruciales de la propuesta pedagógica de Berquin: a la descripción de los estadios iniciales del aprendizaje moral (las motivaciones de los personajes secundarios, la caracterización de los protagonistas, la descripción de las acciones y actitudes infantiles) y al intercambio lingüístico entre los personajes.

En su tesis sobre Berquin, Baudron (2009) se pregunta si Berquin fue autor, adaptador o traductor y podríamos hacernos la misma pregunta acerca de Viera y Clavijo. La moraleja de los cuentos traducidos es la misma que late en los de Berquin, pero la gran diferencia entre ambos autores radica en el procedimiento pedagógico: Berquin está muy impregnado del sensualismo y de las teorías de Rousseau sobre la pedagogía: con el uso sistemático del método socrático pretende acompañar al niño lector en su aprendizaje en vez de imponerle unas verdades dictadas por adultos. Para cumplir esta misión recurre al juego de preguntas/respuestas, privilegia la práctica sobre la teoría, recurre a los sentidos, a la emoción -muy de moda en la comedia lacrimógena de su tiempo (Mauclair, 2000) -, herramientas pedagógicas que Viera y Clavijo deja con frecuencia de lado para privilegiar el hilo narrativo y sintetizar el mensaje, la moraleja explícita. Berquin varía los métodos pedagógicos: valorar al niño (como en el cuento "L'esprit de contradiction "), reconocer el error como forma de aprendizaje ( Philippine et Maximin»), aprovechar la observación para una enseñanza científica ("Les deux pommiers », " La neige »), valorar la complicidad entre maestro y aprendiz (rasgo que podríamos relacionar con la masonería, a la que Berquin pertenecía) por encima de la autoridad del preceptor ("Les buissons»).

Casi se podría decir que Viera y Clavijo propone un " prêt à penser » que no obligue tanto al lector español como al francés a reflexionar y esperar con paciencia a que por fin pueda dar a luz a la verdad. Se criticó a Berquin por ser demasiado demostrativo (Baudron, 2009: 12), y en este aspecto Viera y Clavijo presenta una actitud muy diferente: no cuida tanto las demostraciones, quizá por considerar que eran superfluas en la transmisión del mensaje moral, que lo diluían en vez de hacerlo más impactante o quizá por creer que los cuentos de Berquin no respondían al horizonte de expectativas de los niños, por ser demasiados largos.

Mención aparte merecen las atenuaciones que se refieren a la expresión de la sensibilidad. Como ya indicaba Cioranescu (1954: 221-248), Viera suele sacrificar sistemáticamente, en sus traducciones, los pasajes descriptivos y las descripciones en general, así como los aspectos más sentimentales, en consonancia con su temperamento. Efectivamente, es llamativo comprobar cómo Viera y Clavijo suele mitigar las descripciones que afectan a la descomposición del rostro o sustituir las referencias a la 
prisa por otras actitudes que reflejan algo de vehemencia pero no el dinamismo del original. Berquin describe con gran detenimiento los cambios de ánimo, las efusiones de cariño, la dimensión emocional a la que Berquin recurre para sensibilizar aún más al lector, que puede estar relacionado con la moda de la comedia lacrimógena de la segunda mitad del siglo XVIII y que anuncia ya el romanticismo (Mauclair, 2000). Menos cercano al próximo Romanticismo, Viera refleja quizá un mundo más hierático e impasible en la gestualidad, probablemente en la intención de educar la sensibilidad de los niños de las clases dominantes españolas en una tradición bien asentada que explica también la seriedad en los retratos pictóricos de la época.

En relación con este encuadre de Viera más en la Ilustración que en el prerromanticismo, en el que sí podríamos situar a Berquin, podemos señalar algunos cambios observados en la traducción que relacionan a Viera con las expresiones cultistas propias de Barroco y que, como es sabido, se prolonga a lo largo de todo el siglo XVIII en España.

En suma, y ya que hemos percibido importantes divergencias entre original y traducción en cuanto a hábitos sociales, formas de exteriorización de la afectividad, sensibilidades, propósitos didácticos e ideología, permítasenos concluir apropiándonos de la inteligente metáfora de los afeites y vestidos empleada por Viera en una carta de 1778 al marqués de San Andrés (Viera, 2008a: 158) para hablar de las diferencias entre las sociedades francesa y española, sin esconder su clara preferencia por la primera y la insoslayable necesidad de acomodarse a la segunda, a su pesar, en cuanto a costumbres, sensibilidades e ideas:

Confieso que mi vuelta a estos reinos antes del tiempo proyectado dejando la compañía de los duques del Infantado y las delicias francesas y dejando las ínfulas abaciales del Rabat, calota, polvos, bucles... para reasumir las sopalandas y el sombrero de canal sobre una cabeza villana y mugrienta, no ha sido de mucho contentamiento para mí. Pero, acostumbrado a gozar y a abstenerme, a buscarlo todo dentro de mí y dejarme llevar tranquilamente de la corriente de los sucesos, me he resignado en volver a donde la tierra no se mueve sino el Sol (Viera, 2008a: 158).

\section{REFERENCIAS BIBLIOGRÁFICAS}

BAUDRON, Annette (2009): L'auvre d'Arnaud Berquin; Littérature de jeunesse et esprit des Lumières. Thèse de doctoratsous la direction de Jean-Jacques Tatin-Gourier. Tours, Université François Rabelais.

BERQUin, Arnaud (1782 a 1783): L'Ami des enfants, par M. Berquin. Paris, Pissot \& Teophile Barrois. Disponible en: https://gallica.bnf.fr/ark:/12148/cb424149065/date.

Bravo-Villasante, Carmen (1983): "Berquin en Espagne », in D. Escarpit (dir.), Arnaud Berquin 1747-1791 Bicentenaires de L'Ami des enfants. Pessac, Nous voulons lire, 64- 
69.

CERVERA, Juan (1976): Historia crítica del teatro infantil español. Madrid, Editora Nacional. Disponible en: http://www.cervantesvirtual.com/nd/ark:/59851/bmcfq9r7.

CiORANESCU, Alejandro (1954): Estudios de Literatura española y comparada. La Laguna, Universidad de La Laguna.

DÍAZ ARMAS, Jesús y Patricia MAUCLAIR (2018): «Los inicios de la literatura infantil en España: José de Viera y Clavijo». Ocnos, 17 (2), 82-91. DOI: 10.18239/ocnos_2018.17.2.1594.

FERNÁNDEZ HERNÁNDEZ, Rafael (1991): Teatro canario, I (siglo XVI al XX). Las Palmas de Gran Canaria, Edirca.

GALVÁn GONZÁlEZ, Victoria (2005): «La Historia Natural en la obra de José de Viera y Clavijo», in J. de Viera y Clavijo, Diccionario de Historia Natural de las Islas Canarias, La Laguna, Nivaria, XV-LXXXIV.

GALVÁN GONZÁLEZ, Victoria [ed.] (2009): Viera al trasluz. Santa Cruz de Tenerife, Idea.

HAVELANGE, Isabelle e Isabelle Nières-CHEVREL (2014): "Livres pour l'enfance et la jeunesse », in Y. Chevrel, A. Cointre y Y.-M. Tran-Gervat (dirs.), Histoire des traductions en langue française. XVIT et XVIII siècles. 1610-1815. Lagrasse, Éditions Verdier, 1211-1281.

HERNÁNDEZ, Manuel (2002): «Estudio preliminar», in J. de Viera y Clavijo, Opúsculos científicos. Noticias del cielo o astronomía para niños. Los ayres fixos. Las bodas de las plantas, La Orotava, Fundación Canaria Orotava de Historia de la Ciencia (col. Materiales de Historia de la Ciencia), 7-49.

LHÉRÉTÉ, Annie (1985): «Arnaud Berquin, un traducteur à la fin du XVIII siècle ». Cahiers du CERULEJ, 1, 71-85.

MARTIN, Angus (1974): "Notes sur L'Ami des enfants de Berquin et la littérature enfantine en France aux alentours de 1780 ». Dix-huitième siècle, 6, 299-308.

MAUClaIR, Patricia (2000): "Le plaisir des larmes, un plaisir vertueux », in S. Salaün y F. Etienvre (coords.), Le(s) plaisir(s) en Espagne au théâtre en Espagne au XVIII siècle, París, CREC-Université de la Sorbonne Nouvelle, 36-56. Disponible en: http://crecparis3.fr/wp-content/uploads/2011/07/02-Mauclair.pdf.

NEGRÍN FAJARDO, Olegario (1993): «Un proyecto ilustrado de transformación de la realidad educativa canaria: el Síndico Personero de Viera y Clavijo», in IX Coloquio de Historia Canario-Americana (1990), t. II. Las Palmas de Gran Canaria, Cabildo Insular de Gran Canaria, 919-946.

NIDA, Eugene Albert (1964): Toward a Science of Translating with special Reference to Principles and Procedures Involved in Bible Translating. Leiden, E. J. Brill.

NiÈrES-CHEVREL, Isabelle (2014): "Des sources nouvelles pour L'Ami des enfants de Berquin ». Revue d'Histoire Littéraire de la France, 214 (4), 807-828. DOI: 10.3917/rhlf.144.0807.

PADRÓN, Rafael (2019): «Europa a la vista: Viera y Clavijo en el Grand Toun», in R. Padrón (ed.), Viera y Clavijo. De isla en continente. Santa Cruz de Tenerife, Viceconsejería de 
Cultura y Deportes del Gobierno de Canarias, 449-501.

RUIZ CASANOVA, J. F. (2018): Ensayo de una historia de la traducción literaria en España. Madrid, Cátedra.

RUIZ DE LA PEÑA, Álvaro (2003): «Ilustración, lectura y juventud en la España del siglo XVIII», in V. Infantes, F. López, y J. F. Botrel (eds.), Historia de la edición y de la lectura en España. 1472-1914. Madrid, Fundación Germán Sánchez Ruipérez, 493-503.

SAVORY, Theodore H. (1968): The Art of Translation. Londres, Jonathan Cape.

SORIANO, Marc (1999): La literatura para niños y jóvenes. Guía de exploración de sus grandes temas. Traducción, adaptación y notas de G. Montes. Buenos Aires, Colihue.

SOUBEYROUX, Jacques (2011): «Tomás de Iriarte traducteur de Campe: El nuevo Robinsón para instrucción y entretenimiento de niños y jóvenes de ambos sexos (1789) », in Ch. Pérès (coord.), Grands auteurs pour petits lecteurs. Adapter, traduire et illustrer les grands auteurs dans la littérature de jeunesse en langue espagnole. Toulouse, Lansman-Université Toulose-Le Mirail, 155-168.

URZAINQUI, Inmaculada (1991): «Hacia una tipología de la traducción en el siglo XVIII: los horizontes del traductor», in M. L. Donaire, y F. Lafarga (eds.), Traducción y adaptación cultural: España-Francia. Oviedo, Universidad de Oviedo, 623-638.

VALLEJO-NÁGERA, AlejANDRA (2006): Locos de la historia: Rasputín, Luisa Isabel de Orleáns, Mesalina y otros personajes egregios. Madrid, Esfera de los Libros.

VIERA y ClaVijo, José (1803): Cuentos de niños que instruyen divirtiendo: obra extractada de buenos autores, principalmente de la que con el título del Amigo de los niños publicó en Paris Mr. Berquin, y fue premiada por la Academia francesa como una de las más útiles para la educación. Dada a luz por Dn. José de Viera y Clavijo, arcediano de Fuerteventura, Dignidad de la Sma. Iglesia de Canaria y director de su R. Sociedad. Año de 1804 [s.l.], [s.e.], [s.a.]. Disponible en: https://hermes.bbtk.ull.es/pandora/cgi-bin/Pandora.exe?fn$=$ select $\% 3$ bcollection $=$ manuscritos $\% 3$ bquery=alt_record_id:0576522_00000_0000\% 3bxslt $=$ vid.

VIERA Y ClaVijO, José (2008a): Vos estis Sol. Epistolografia intima (1770-1783). Ed. Rafael Padrón Fernández. Madrid, Consejo Superior de Investigaciones Científicas.

Viera y ClaVijo, José (2008b): Diario de viaje a Francia y Flandes. Edición de Rafael Padrón Fernández. La Laguna, Instituto de Estudios Canarios.

Viera y ClaVIjO, José (2012): Memorias, in Obras Completas de Viera y Clavijo. Edición de Rafael Padrón Fernández. Santa Cruz de Tenerife-Las Palmas de Gran Canaria, Idea, t. I.

Viera y ClaVijo, José (2013): Obra didáctica, in Obras completas de Viera y Clavijo. Edición de T. Acosta Tejera y V. Aguiar Bobet. Santa Cruz de Tenerife-Las Palmas de Gran Canaria, Idea, t. XXIII. 


\section{ANEXO I}

\section{Textos mencionados}

El número entre paréntesis al lado del título en español corresponde al lugar de inicio del texto en la edición de 1803, conservada en la Biblioteca de la Universidad de La Laguna. La información entre paréntesis junto al título francés remite a la entrega mensual correspondiente de la publicación periódica L'Ami des enfants (año/ mes, página inicial).

\begin{tabular}{|c|c|}
\hline Título EN LA TRADUCCIÓN DE VIERA & Título en la COleCCión de ARNAUd BERQUin \\
\hline Amador (p. 24) & Amand $(1782 / 01,47)$ \\
\hline Carlota (p. 73) & Caroline $(1782 / 04,27)$ \\
\hline Clementina y Magdalena (p. 52) & Clémentine et Madelon $(1782 / 03,5)$ \\
\hline Dionisia y Antonino (p. 89) & Denise et Antonin $(1782 / 06,29)$ \\
\hline Dios siempre te ve (p. 115) & $\begin{array}{l}\text { Si les hommes ne te voient pas, Dieu te voit } \\
(1782 / 08,45)\end{array}$ \\
\hline El almuerzo (p. 168) & Le déjeuner $(1983 / 04,5)$ \\
\hline El arrendatario (p. 75) & Le fermier $(1782 / 04,30)$ \\
\hline El canario (p. 30) & Le serin $(1782 / 02,5)$ \\
\hline El contratiempo útil (p. 96) & Le contretemps utile $(1782 / 06,42)$ \\
\hline El criado antiguo (p. 84) & Le vieux Champagne $(1782 / 06,5)$ \\
\hline El desaliño (p. 223) & Le désordre et la malpropreté $(1983 / 09,53)$ \\
\hline Él es una alhaja (p. 232) & [De fuente aún no identificada] \\
\hline El espíritu de contradicción (p. 132) & L'esprit de contradiction $(1782 / 11,23)$ \\
\hline El gusto de trabajar (p. 99) & Les douceurs du travail $(1782 / 08,5)$ \\
\hline El hermanito (p. 3) & Le petit frère $(1782 / 01,1)$ \\
\hline El mentiroso (p. 199) & Le menteur corrigé par lui-même $(1983 / 04,98)$ \\
\hline El nido de jilgueros (p. 212) & Le nid de fauvette $(1983 / 04,133)$ \\
\hline El nido de pájaros (p. 104) & Le nid de moineaux $(1782 / 08,25)$ \\
\hline El rosal de Alejandría (p. 181) & $\begin{array}{l}\text { Le rosier à cent feuilles et le genêt d'Espagne } \\
(1983 / 04,43)\end{array}$ \\
\hline El vestido de seda (p. 144) & Le fourreau de soie $(1782 / 11,61)$ \\
\hline Felipa y Maximino (p. 61) & Philippine et Maximin $(1782 / 04,5)$ \\
\hline La atención y complacencia (p. 206) & Les ègards et la complaisance $(1983 / 04,123)$ \\
\hline La avecita de Dios (p. 196) & Loiseau du Bon Dieu $(1983 / 04,90)$ \\
\hline La bachillera (p. 190) & Le petite babillarde $(1983 / 04,74)$ \\
\hline
\end{tabular}




\begin{tabular}{|c|c|}
\hline Título EN LA TRADUCCIÓN DE VIERA & Título en la ColeCCión de ARNAUd BERQUin \\
\hline La charladora (p. 219) & Les caquets $(1983 / 08,34)$ \\
\hline La cicatriz (p. 141) & La cicatrice $(1782 / 11,53)$ \\
\hline La cordera (p. 66) & L'agneau $(1782 / 04,14)$ \\
\hline La cuelga (p. 187) & Le cadeau $(1983 / 04,55)$ \\
\hline La espada (p. 235) & L'épée (1982/03, 93) \\
\hline La fisonomía (p. 119) & La physionomie $(1782 / 09,5)$ \\
\hline La gallina (p. 122) & La poule $(1782 / 10,5)$ \\
\hline La muñeca (p. 163) & Euphrasie $(1783 / 02,133)$ \\
\hline La nieve (p. 16) & La neige $(1782 / 01,31)$ \\
\hline La niña con bigotes (p. 137) & La petite fille à moustaches $(1782 / 11,48)$ \\
\hline La niña regañona (p. 92) & La petite fille grognon $(1782 / 06,33)$ \\
\hline La peluca y los zancos (p. 228) & $\begin{array}{l}\text { La perruque, le gigot, les lanternes, les sacs } \\
\text { d'avoine et les échasses }(1983 / 11,5)\end{array}$ \\
\hline La piedad filial (p. 129) & L'amour de Dieu et de ses parens $(1782 / 10,56)$ \\
\hline La vid (p. 69) & Le cep de vigne $(1782 / 04,20)$ \\
\hline Las botas enlodadas (p. 216) & Les bottes crottées $(1983 / 08,28)$ \\
\hline Las cuatro estaciones (p. 12) & Les quatre saisons $(1782 / 01,22)$ \\
\hline Las fresas y las grosellas (p. 203) & Les fraises et les groseilles $(1983 / 04,119)$ \\
\hline Los dos manzanos (p. 110) & Les deux pommiers $(1782 / 08,38)$ \\
\hline $\begin{array}{l}\text { Los muchachos que hacen su gusto (p. } \\
\text { 39) }\end{array}$ & $\begin{array}{l}\text { Les enfants qui veulent se gouverner eux-mêmes } \\
(1782 / 02,24)\end{array}$ \\
\hline Los ramilletes (p. 184) & Les bouquets $(1983 / 04,48)$ \\
\hline Los zarzales (p. 46) & Les buissons $(1782 / 02,48)$ \\
\hline Mariposa bella (p. 179) & Papillon, jolie papillon! $(1983 / 04,31)$ \\
\hline Nuestro gran jardín (p. 151) & Le grand jardin $(1782 / 12,5)$ \\
\hline ¡Quita allá tu almíbar rabioso! (p. 175) & Fi ! Le vilain charmant! $(1983 / 04,24)$ \\
\hline
\end{tabular}


Para citar este artículo / Pour citer cet article :

MAUClair, Patricia \& Jesús DíAz ARMAS (2019) : "Literatura ad usum delphini: José de Viera y Clavijo y su traducción de los cuentos para niños de Arnaud Berquin». Çédille, revista de estudios franceses, 16, 347-380. DOI: https://doi.org/10.25145/j.cedille.2019.17.16.21. 